\title{
A TEORIA DA LEGITIMIDADE E O CUSTO POLÍTICO NAS EVIDENCIAÇÕES CONTÁBEIS DOS GOVERNOS ESTADUAIS DA REGIÃO SUDESTE DO BRASIL
}

\section{LEGITIMACY THEORY AND POLITICAL COSTS IN ACCOUNTINGS STATEMENTS FROM STATE GOVERNMENTS IN THE SOUTHEASTERN REGION OF BRAZIL}

\author{
ILSE MARIA BEUREN \\ Doutora em Controladoria e Contabilidade pela \\ Universidade de São Paulo \\ Professora Titular do Centro de Ciências Sociais e Aplicadas da \\ Universidade Regional de Blumenau \\ Blumenau/SC, Brasil \\ E-mail: ilse@furb.br
}

\author{
ARI SÖTHE \\ Mestrando em Ciências Contábeis na \\ Universidade Regional de Blumenau \\ Blumenau/SC, Brasil \\ E-mail: ari_sothe@yahoo.com.br
}

\section{Resumo}

A entidade pública se utiliza da evidenciação de informações contábeis compulsórias e voluntárias para atender as exigências dos órgãos fiscalizadores e permitir que a sociedade acompanhe os resultados da gestão, buscando ampliar ou recuperar a legitimidade de seus atos e minimizar o custo político. O estudo tem como objetivo analisar a evidenciação de informações contábeis compulsórias e voluntárias que os governos estaduais da região sudeste do Brasil disponibilizam em suas páginas eletrônicas. Foi realizada pesquisa exploratória com abordagem qualitativa, por meio da análise das evidenciações compulsórias, conforme estabelecido pela Lei $n^{\circ}$ 9.755/1998 e Lei Complementar $n^{\circ}$ 101/2000, e voluntárias. Também foram analisadas as características qualitativas das informações contábeis definidas pelo Comitê de Pronunciamentos Contábeis (CPC) em seu Pronunciamento Conceitual Básico: compreensibilidade, relevância, confiabilidade e comparabilidade das demonstrações. Para determinar os níveis de evidenciação contábil, consideraram-se as categorias estabelecidas por Hendriksen e Van Breda (1999), que consistem de divulgação adequada, justa e completa. Os resultados da pesquisa denotam que a evidenciação de informações contábeis nas páginas eletrônicas não atende de forma completa as quatro características qualitativas e nem mesmo os três níveis de evidenciação pesquisados.

Palavras-chave: Teoria da Legitimidade; custo político; evidenciações contábeis.

\section{Abstract}

Public entities used compulsory and voluntary financial statements to attend to the demands of fiscal inspectors and to allow society to follow the results of management, seeking to widen or recuperate legitimacy of their actions and to reduce public costs. The objective of the current study was to analyze compulsory and voluntary financial statements that state governments from the southeastern region of Brazil have made available on their electronic pages. Exploratory research using a qualitative approach was made, by means of analysis of compulsory disclosures, according what was established in Law $\mathrm{n}^{\circ}$ 9.755/1998 and Complementary Law $n^{\circ} 101 / 2000$, and voluntary disclosures. Qualitative characteristics from accounting information defined by the Committee on Accounting Pronouncements (CPC) in the Basic Conceptual Pronunciation: comprehensibility, relevance, reliability and comparability of statements were also analyzed. In order to determine the levels of accounting disclosure, the categories established by Hendriksen and Van Breda (1999), which consist of disclosure, adequacy and fair and complete were considered. Research results denote that disclosure of accounting information on electronic pages does not meet in a complete way the four qualitative characteristics, nor does it even meet the three levels of disclosure researched.

Key words: Legitimacy Theory, political cost, accounting statements. 


\section{INTRODUÇÃO}

As evidenciações contábeis compreensíveis e úteis permitem que as entidades apresentem informações de modo a diminuir a assimetria informacional entre os diversos usuários. Lopes e Martins (2007) destacam que "os gestores possuem mais informações sobre as entidades que os demais usuários e a contabilidade é utilizada pelos gestores para informar de forma seletiva os aspectos mais interessantes da empresa". Assim o gestor poderá por meio das evidenciações contábeis limitar ou ampliar a compreensão aos demais usuários.

A teoria da legitimidade, conforme Dias Filho (2007, p. 6), "baseia-se na idéia de que existe uma espécie de contrato social entre as organizações e a sociedade em que atuam, representando um conjunto de expectativas implícitas ou explícitas de seus membros a respeito da forma como elas devem operar". Uma forma da entidade demonstrar o cumprimento deste contrato é por meio das evidenciações contábeis.

Quando a entidade não realiza as suas atividades em conformidade com o que a sociedade espera, torna-se necessário a ampliação dos níveis de evidenciação e gera-se o aumento dos custos políticos. Silva e Sancovschi (2006) relatam que por meio da inclusão de informações sociais nos relatórios anuais os gestores procuram evitar a intervenção política.

Frey e Frey (2004) analisaram a forma como uma empresa brasileira com alto custo político, a Souza Cruz S.A., empresa que fomenta a plantação do tabaco e fabrica cigarros, utilizou a evidenciação voluntária de informações sociais em seus relatórios anuais, no período de 1993 a 2002, para encaminhar questões negativas relacionadas com seus produtos, frente a uma possível ameaça ou perda de legitimidade.

Dentro desta mesma ótica Silva e Sancovschi (2006) analisaram como a empresa Petróleo Brasileiro S.A. utilizou a evidenciação voluntária de informações sociais em seus relatórios anuais, no período de 1993 a 2002, para encaminhar questões relacionadas com sua atividade, frente a uma possível ameaça ou perda de legitimidade.

Outro estudo, realizado por Bispo et al. (2007), discute a relação entre carga tributária, os setores econômicos, os tamanhos das empresas brasileiras e o custo político do enquadramento da empresa nestes ambientes. Os três estudos apresentados abordaram a legitimidade organizacional e o custo político em empresas privadas.

No âmbito da transparência pública Platt Neto, Cruz e Vieira (2006) realizaram um estudo com o objetivo de caracterizar e apresentar considerações sobre o uso da Internet como instrumento de publicidade aliado à transparência das contas públicas das universidades brasileiras. 0 presente estudo diferencia-se dos realizados anteriormente, pois busca estudar as evidenciações contábeis compulsórias e voluntárias de entidades públicas estaduais e o custo político da manutenção da legitimidade.

Assim elaborou-se a seguinte questão de pesquisa: Quais são as evidenciações contábeis compulsórias e voluntárias que os governos estaduais disponibilizam em suas páginas eletrônicas? 0 estudo tem como objetivo analisar a evidenciação de informações contábeis que os governos estaduais da região sudeste do Brasil disponibilizam em suas páginas eletrônicas.

Neste sentido foi realizado um estudo exploratório, com análise de conteúdo das informações disponibilizadas nos sítios dos governos estaduais selecionados. $\mathrm{Na}$ interpretação dos dados disponibilizados, foram avaliados os níveis de evidenciação contábil compulsória e voluntária disponíveis em suas páginas eletrônicas e as características qualitativas dessas informações contábeis evidenciadas. 
0 estudo se justifica pela necessidade de avaliação da quantidade e qualidade das informações disponibilizadas pelos órgãos públicos por meio de seus sítios, levando em consideração a ampliação dos níveis de acesso da sociedade a este tipo de mídia. Outro elemento relevante é a avaliação do cumprimento da legislação pelos órgãos públicos referente às publicações contábeis compulsórias, as possíveis evidenciações voluntárias e o custo político para a manutenção da legitimidade dos atos do gestor público.

A escolha das páginas eletrônicas dos governos estaduais da região sudete do Brasil se justifica, pois ela corresponde à região mais populosa do país. Portanto, presume-se que as evidenciações disponibilizadas atendem um maior número de usuários, logo são mais visadas que as páginas de estados menores em termos populacionais. Embora se entenda que todo gestor público deva ter preocupações com seus atos, órgãos públicos maiores geralmente possuem mais recursos disponíveis para cuidar da evidenciação desses atos.

0 estudo está organizado em cinco seções, iniciando com essa introdução. Em seguida apresenta a fundamentação teórica que serviu de sustentação à pesquisa. $\mathrm{Na}$ seqüência apresenta os aspectos metodológicos utilizados para desenvolver a pesquisa. Após faz a descrição, análise e interpretação dos dados coletados. Por último, apresenta as conclusões do estudo realizado e recomendações para futuras pesquisas sobre o tema investigado.

\section{FUNDAMENTAÇÃO TEÓRICA}

O aumento dos níveis de evidenciação contábil das organizações surge pela importância de satisfazer as diversas necessidades dos mais variados tipos de usuários da informação. Para a verificação da quantidade da informação apresentada pelas demonstrações é necessária a avaliação dos níveis de evidenciação. Por sua vez, a avaliação da qualidade destas demonstrações pode ser verificada por meio do conjunto de características qualitativas que elas apresentam.

No entanto, a evidenciação das informações contábeis constantemente está revestida de elementos que influenciam os gestores para o aumento ou diminuição desses níveis. $\mathrm{O}$ aumento de evidenciações contábeis pode ter como intuito diminuir o impacto negativo na sociedade de algum evento, ou mesmo, para demonstrar aos usuários que a entidade está atendendo o que a legislação estabelece. A teoria da legitimidade e a hipótese dos custos políticos abordam elementos que levam atores sociais a agir de determinada forma para recuperar ou manter sua reputação social.

\subsection{TEORIA DA LEGITIMIDADE E HIPÓTESE DOS CUSTOS POLÍTICOS}

Watts e Zimmerman (1978, apud RIBEIRO et al., 2008) esclarecem que a hipótese dos custos políticos presume que "grandes empresas inseridas em setores sensíveis a questões políticas tais como, a indústria farmacêutica, o setor de serviços públicos, o setor florestal e a indústria de petróleo e gás, estão sujeitas a custos políticos potencialmente elevados, relacionados à evidenciação de ganhos elevados". Os mesmos autores destacam que esses custos políticos são decorrentes de aspectos contratuais e de lobbies, e provenientes da regulação do Estado para as atividades da firma.

A observação política da empresa poderá se refletir na utilização de procedimentos contábeis alternativos, que busquem diminuir imediatamente o seu lucro. ludícibus e Lopes (2004, p. 25) citam que: 
Presumindo-se que as demais variáveis permaneçam inalteradas, se os administradores considerarem que a empresa está sob forte observação de natureza política e que isto poderá acarretar custos elevados, tenderão a optar por procedimentos contábeis que desloquem lucros do presente para períodos futuros. Portanto, essa hipótese introduz um componente político na escolha dos procedimentos contábeis de determinadas empresas.

Segundo a teoria dos custos políticos, de acordo com Key (1997), à medida que uma empresa está sujeita à transferência potencial de riqueza, a hipótese da gestão é adotar procedimentos contábeis que reduzam essa transferência. No entanto, ao gerenciar o resultado há preocupação com o custo político decorrente, uma vez que o comparativo dos lucros de empresas pode denunciar manobras contábeis, por exemplo, para reduzir o pagamento de impostos ou aumentar a participação dos gestores no resultado.

Presume-se que o aumento dos lucros gera um aumento na atenção da sociedade, governo, imprensa, consumidores, entre outros. Para os segmentos da sociedade, o aumento dos lucros poderá estar associado à sonegação de impostos, degradação ambiental, exploração da mão-de-obra, entre outros. A empresa, desta forma, estará propensa a penalidades por meio de sanções econômicas ou imposições de multas, aumento da tributação, reajustes salariais e outros que elevarão os seus custos (IUDíCIBUS; LOPES, 2004).

Os lucros e tamanho da empresa podem ser associados ao aumento dos custos políticos, como por exemplo, o aumento da carga tributária. No entanto, não representam necessariamente os únicos. Em decorrência, a organização poderá lançar mão às formas alternativas de contabilização para a redução do custo político proveniente do aumento da carga tributária. Um exemplo de hipótese de custo político é que administradores de empresas de grande porte são mais propensos a adotar políticas contábeis conservadoras do que administradores de empresa menores (IUDíCIBUS; LOPES, 2004).

Organizações com custos políticos potencialmente elevados, embora não seja uma prerrogativa exclusivamente delas, quando se sentem ameaçadas na sua legitimidade, necessitam e procuram ampliar as evidenciações compulsórias e voluntárias, recuperando ou diminuindo a possibilidade de perda da legitimidade. A legitimidade é definida por Daft (1999, p. 347) como "a perspectiva de que as ações de uma organização são desejáveis, corretas e apropriadas dentro do sistema de normas, valores e crenças do ambiente".

A teoria da legitimidade e a hipótese do custo político, de acordo com Silva e Sancovschi (2006, p. 4), "ajudam na explicação do aumento da evidenciação social, principalmente quando existe pressão pública sobre as empresas para serem ou parecerem mais responsáveis nos campos social e ambiental". Pressupõe-se que os gestores ampliam as evidenciações de aspecto social, ampliando a sua legitimidade e evitando a intervenção política em suas atividades.

Silva e Sancovschi (2006, p. 3) destacam que "o desejo dos administradores de evitar ou reduzir a intervenção política, por exemplo, pode influenciar também a quantidade e a natureza da evidenciação social e ambiental apresentada pelas empresas". 0 aumento da evidenciação pode ser um meio de impedir a intervenção política e reguladora do Estado, principalmente para empresas suscetíveis ao ambiente político.

Igualmente o ente público está sendo fiscalizado constantemente pela sociedade e, por conseguinte, precisa prestar atenção nos custos políticos e na legitimidade de seus atos. Por exemplo, a aplicação de recursos fora dos limites estabelecidos pela legislação ou de forma inadequada, representará uma possível perda de legitimidade e aumento do custo político por parte do ente público. 


\title{
2.2 TEORIA DA LEGITIMIDADE E A EVIDENCIAÇ̃̃O COMO ELEMENTO DA TRANSPARÊNCIA DA GESTÃO EM ENTIDADES PÚBLICAS
}

As teorias são abstrações da realidade, logo não se pode esperar que elas forneçam explicações absolutamente completas para certos comportamentos ou descrições perfeitas de alguns fenômenos. Desse modo, é importante considerar a possibilidade de realizar investigações sob a perspectiva de teorias alternativas. Dias Filho (2007, P. 2) destaca que "um dos recursos teóricos que têm sido propostos nos últimos anos como alternativa para explicar e predizer práticas de evidenciação voluntária é a Teoria da Legitimidade”.

Deegan e Rankin (1996, apud DIAS FILHO, 2007, p. 7) destacam que na ótica da teoria da legitimidade, "se uma organização não puder justificar a sua continuidade perante a sociedade, gradativamente os seus membros se encarregarão de revogar o contrato social". Assim a organização necessita demonstrar constantemente à sociedade a sua importância e legitimando os seus atos, evidenciando o cumprimento do contrato social existente entre a sociedade e a empresa.

A avaliação e julgamento pela sociedade das ações das organizações tornam-se um incentivo ao aumento da legitimidade. Silva e Sancovschi (2006, p. 2) afirmam que:

\begin{abstract}
A grande probabilidade de trocas adversas na percepção da sociedade de como uma organização está agindo, opera como um fator de incentivo para os administradores tentarem gerenciar a legitimidade de sua empresa. Assim, quando ocorrer uma ameaça presente ou potencial à legitimidade da empresa decorrente de um evento negativo, os administradores podem tentar mudar a percepção dos que estão do lado de fora, com o objetivo de aumentar a congruência entre as atividades da organização e a expectativa da sociedade.
\end{abstract}

As empresas privadas são incentivadas a ampliar as suas evidenciações atraindo investidores, financiadores e legitimando suas ações sociais e ambientais. Para ludícibus (2004, p.123), a evidenciação ou disclosure "está ligado aos objetivos da contabilidade, ao garantir informações diferenciadas para os vários tipos de usuários". Esta definição é adequada quando se objetiva o estudo dos níveis de evidenciação contábil, seja ela compulsória ou voluntária na administração pública.

Aquino e Santana (1992, p. 10) destacam que “o processo de evidenciação de informações, a determinação de sua natureza e extensão, também estão relacionados com a forma em que são estabelecidos os princípios e práticas contábeis". Exemplificam, "se decorrentes de exigências legais, se por consenso de organismos profissionais, pressões dos usuários, ou por um misto desses fatores".

Dantas, Zendersky e Niyama (2004, p. 2) advertem que evidenciação "não significa apenas divulgar, mas divulgar com qualidade, oportunidade e clareza". Destacam ainda que, para alcançar a transparência pretendida com o disclosure, "a instituição deve divulgar informações qualitativas e quantitativas que possibilitem aos usuários formar uma compreensão das atividades desenvolvidas e dos seus riscos, observando aspectos de tempestividade, detalhamento e relevância necessários".

A apresentação do que é relevante ao usuário da informação pode ser tanto por meio da utilização das evidenciações voluntárias como de evidenciações compulsórias, mas principalmente deve estar presente no primeiro grupo. ludícibus (2004) destaca que é preciso prestar atenção na relevância das informações divulgadas, sendo necessário que se informe o que realmente é importante para o usuário.

A evidenciação compulsória está vinculada às informações que a legislação exige para que os usuários possam obter o mínimo de informações úteis. Boff (2007, p. 38) 
esclarece que "a evidenciação compulsória representa as informações requeridas legalmente pelos órgãos de regulamentação e pelos órgãos de classe".

As informações entre parênteses, notas de rodapé, quadros e demonstrativos suplementares são formas de evidenciação das informações contábeis que continuam sendo voluntárias apesar de sua larga utilização ao longo do tempo, servindo como complemento às informações apresentadas pelas demonstrações contábeis compulsórias (DALMÁCIO; PAULO, 2004, p. 79).

Quanto ao nível de evidenciação a ser utilizado, Hendriksen e Van Breda (1999, p. 515) descrevem que "o nível de divulgação também depende do padrão considerado mais desejável. Três conceitos de divulgação são geralmente propostos: divulgação adequada, justa e completa". No escopo desse estudo as três formas de divulgação são aplicáveis.

A legislação determina a apresentação mínima das informações contábeis, sendo apresentadas de forma padronizada para tratar igualmente todos os usuários da informação. No entanto, a legislação não inibe a divulgação completa. Assim deve ser incentivada a divulgação completa, no sentido de proporcionar aos gestores a apresentação de todas as informações que julgarem relevantes. No Quadro 1 são apresentadas as definiçõos de cada nível de evidenciação.

\begin{tabular}{|c|l|}
\hline Níveis de Evidenciação & \multicolumn{1}{c|}{ Definição } \\
\hline Adequada & $\begin{array}{l}\text { Volume mínimo de divulgação para as demonstrações não } \\
\text { serem consideradas enganadoras. }\end{array}$ \\
\hline Justa & Trata igualmente os leitores em seu potencial. \\
\hline Completa & Pressupõe a apresentação de toda a informação relevante. \\
\hline
\end{tabular}

Quadro 1 - Níveis de evidenciação da informação contábil

Fonte: elaborado com base em Hendriksen e Van Breda (1999).

Hendriksen e Van Breda (1999) comentam que o excesso de informação pode ser prejudicial da mesma forma que a sua falta. Desta forma a informação relevante apropriada para os usuários deve ser adequada, justa e completa.

Para Hendriksen e Van Breda (1999, p. 515), “num mundo ideal, as decisões sobre o nível apropriado de divulgação seriam baseadas no aumento do bem-estar social que qualquer divulgação adicional produzisse". Com o aumento da divulgação das informações de caráter contábil e social, o principal usuário desta informação (cidadão), consegue visualizar com facilidade as atividades desenvolvidas pela entidade pública, permitindo o acesso aos serviços oferecidos pela entidade.

É importante que o gestor público avalie as informações a serem divulgadas, sejam elas quantitativas ou qualitativas. As informações de caráter contábil nos órgãos públicos são geralmente apresentadas de forma quantitativa, pois trata-se de uma das características deste tipo de informação. De outro lodo as informações de caráter social apresentam características mais qualitativas, uma vez que são apresentadas de forma descritiva e recebem níveis diferenciados de avaliação.

\subsection{EVIDENCIAÇÃO COMPULSÓRIA E EVIDENCIAÇÃO VOLUNTÁRIA EM ENTIDADES PÚBLICAS}

As empresas públicas apresentam diversas características diferenciadas em relação às empresas privadas, entre as quais está a responsabilização social do gestor pelos resultados apresentados pela entidade. Silva e Sancovschi (2006 p. 43), com foco em 
empresas, destacam que a evidenciação social voluntária é "um meio de os administradores proverem informações sobre as atividades, produtos e objetivos de suas empresas de modo a legitimar seu comportamento, especialmente em momentos em que essas empresas tenham suas atividades, seus produtos ou seus objetivos questionados". As entidades públicas, da mesma forma, são incentivadas a ampliar a evidenciação de forma voluntária.

No que refere a evidenciação compulsória, Boff $(2007$, p. 38) cita que ela "representa as informações requeridas legalmente pelos órgãos de regulamentação e pelos órgãos de classe. Esses órgãos estabelecem padrões de evidenciação compulsórios às empresas para garantir um nível informacional mínimo, necessário e exigido pelos usuários". Nas entidades públicas esta evidenciação compulsória é estabelecida inicialmente pela Lei $\mathrm{n}^{\circ} 4.320 / 1964$, que instituiu as normas para elaboração dos orçamentos e balanços das entidades públicas. Em seu art. 89 determina que "a contabilidade evidenciará os fatos ligados à administração orçamentária, financeira, patrimonial e industrial".

Denota-se que esta Lei estabelece a importância da contabilidade pública como fonte de evidenciação das atividades da entidade pública. Da mesma forma quando disciplina a elaboração do orçamento público, a Lei n 4.320/1964 determina que "a lei de orçamento conterá a discriminação da receita e despesa, de forma a evidenciar a política econômico-financeira e o programa de trabalho do governo, obedecidos os princípios de unidade, universalidade e anualidade".

Posteriormente a Lei Complementar $n^{\circ} 101 / 2000$, Lei de Responsabilidade Fiscal (LRF), estabeleceu em seu art. 48 os instrumentos da transparência da gestão pública:

São instrumentos de transparência da gestão fiscal, aos quais será dada ampla divulgação, inclusive em meios eletrônicos de acesso público: os planos, orçamentos e leis de diretrizes orçamentárias; as prestações de contas e o respectivo parecer prévio; o Relatório Resumido da Execução Orçamentária e o Relatório de Gestão Fiscal; e as versões simplificadas desses documentos.

Por meio deste dispositivo pode-se identificar o conjunto de evidenciações compulsórias, que deverão ser divulgadas de maneira abrangente, permitindo o acesso dos seus usuários, inclusive por meios eletrônicos. É evidente que estes relatórios deverão ser divulgados também por meio da rede mundial de computadores.

0 art. 48, em seu parágrafo único, determina que "a transparência será assegurada também mediante incentivo à participação popular e realização de audiências públicas, durante os processos de elaboração e de discussão dos planos, lei de diretrizes orçamentárias e orçamentos". Na determinação desse artigo da lei os órgãos públicos precisam realizar um conjunto de procedimentos obrigatórios que têm como objetivo a transparência dos seus atos. Toledo Júnior (2005, p. 288) descreve que "o controle social do erário é peça básica da Lei de Responsabilidade Fiscal, que para tanto, estabelece intensa agenda de debate popular e de publicidade das contas". 0 incentivo à participação popular é assegurada a partir da aplicação do princípio da publicidade, permitindo que a sociedade participe dos eventos de elaboração das peças orçamentárias e avaliação da sua realização.

A não publicação dentro de tempo hábil do Relatório de Gestão Fiscal acarretará em crime fiscal, conforme estabelece o art. $5^{\circ}$ da Lei $n^{\circ} 10.028 / 2000$, com a imposição de multa e processo por parte do Tribunal de Contas dos Estados.

A Lei $\mathrm{n}^{\circ}$ 9.755/1998 dispõe sobre as evidenciações compulsórias instituídas aos órgãos públicos que deverão ser divulgadas através de homepage na Internet. Para o 
atendimento ao que dispõe a referida lei o Tribunal de Contas da União criou em sua homepage um link de acesso com o título "contas públicas" para a publicação de todas as informações contábeis compulsórias dos órgãos públicos federais, estaduais e municipais.

Os critérios para a divulgação das informações a serem publicadas foram devidamente normatizadas na Instrução Normativa do Tribunal de Contas da União $n^{\circ}$ 28/1999. No Quadro 2 são apresentadas as informações que devem ser disponibilizadas pelos órgãos públicos estaduais por meio da rede mundial de computadores de acordo com a Lei $n^{\circ}$ 9.755/1998.

\begin{tabular}{|c|c|c|}
\hline Descrição da Informação & Fundamento Legal & Prazo para Publicação \\
\hline $\begin{array}{l}\text { - os montantes de cada um dos } \\
\text { tributos arrecadados, os recursos } \\
\text { recebidos, os valores de origem } \\
\text { tributária entregues e a entregar e a } \\
\text { expressão numérica dos critérios } \\
\text { de rateio. }\end{array}$ & $\begin{array}{l}\text { - caput do art. } 162 \text { da Constituição } \\
\text { Federal. }\end{array}$ & $\begin{array}{l}\text { - último dia do segundo mês } \\
\text { subseqüente ao da arrecadação }\end{array}$ \\
\hline $\begin{array}{l}\text { - os relatórios resumidos da } \\
\text { execução orçamentária (R.R.E.O.) }\end{array}$ & $\begin{array}{l}\text { - } \S 3^{0} \text { do art. } 165 \text { da Constituição } \\
\text { Federal. }\end{array}$ & $\begin{array}{l}\text { - sessenta dias após } 0 \\
\text { encerramento de cada bimestre }\end{array}$ \\
\hline $\begin{array}{l}\text { a) os orçamentos do exercício; e } \\
\text { b) os respectivos balanços do } \\
\text { exercício anterior. }\end{array}$ & - art. 112 da Lei $\mathrm{n}^{\circ} 4.320$, de 1964. & $\begin{array}{l}\text { a) } 31 \text { de maio; } \\
\text { b) } 31 \text { de julho de cada ano. }\end{array}$ \\
\hline $\begin{array}{l}\text { a) os resumos dos instrumentos de } \\
\text { contrato ou de seus aditivos; e } \\
\text { b) as comunicações ratificadas pela } \\
\text { autoridade superior. }\end{array}$ & $\begin{array}{l}\text { - caput do art. } 26 \text {, parágrafo único } \\
\text { do art. } 61, \S 3^{\mathrm{o}} \text { do art. } 62 \text {, arts. } 116 \text {, } \\
117,119,123 \text { e } 124 \text { da Lei } \mathrm{n}^{\mathrm{O}} \\
8.666 \text {, de } 21 \text { de junho de } 1993 \text {. }\end{array}$ & $\begin{array}{l}\text { a) quinto dia útil do segundo } \\
\text { mês seguinte ao da assinatura do } \\
\text { contrato ou de seu aditivo; } \\
\text { b) trigésimo dia de sua } \\
\text { ocorrência. }\end{array}$ \\
\hline $\begin{array}{l}\text { - as relações mensais de todas as } \\
\text { compras feitas pela Administração } \\
\text { direta ou indireta. }\end{array}$ & - art. 16 da Lei nº 8.666, de 1993. & $\begin{array}{l}\text { até o último dia do segundo mês } \\
\text { seguinte àquele a que se referir. }\end{array}$ \\
\hline
\end{tabular}

Quadro 2 - Publicações compulsórias dos Estados conforme Lei n 9.755/1998

Fonte: elaboração própria com base no art. $1^{\circ}$ da Lei n 9.755/1998.

É fundamental que o gestor público amplie o nível de transparência dos seus atos, observando o que estabelece o art. 37 da Constituição Federal de 1988, em seu $§ 1^{\circ}$ :

$\S 1^{\circ}$ A publicidade dos atos, programas, obras, serviços e campanhas dos órgãos públicos deverá ter caráter educativo, informativo ou de orientação social, dela não podendo constar nomes, símbolos, ou imagens que caracterizem promoção pessoal de autoridades ou servidores públicos.

Portanto, cabe ao gestor ampliar a publicidade, objetivando a efetiva transparência, observando os limites estabelecidos pela legislação e evitando a promoção pessoal. É necessário também que as evidenciações contábeis apresentem características qualitativas que as tornem úteis aos seus usuários.

\subsection{CARACTERÍSTICAS QUALITATIVAS DAS EVIDENCIAÇÕES CONTÁBEIS}

O Comitê de Pronunciamentos Contábeis (CPC) criado por meio da Resolução do Conselho Federal de Contabilidade (CFC) $n^{\circ}$ 1.055/05, com o objetivo de emissão de pronunciamentos contábeis para a convergência da contabilidade brasileira aos padrões internacionais, em seu Pronunciamento Conceitual Básico, oficializado pela Deliberação da Comissão de Valores Mobiliários (CVM) n 539/2008 e pela Resolução do CFC n 1.121/2008, 
criou a estrutura conceitual para a elaboração e apresentação das demonstrações contábeis, aplicável às entidades públicas e privadas, estabelecendo que as demonstrações contábeis devam atender as necessidades dos seus usuários, entre os quais se destacam os investidores, credores, fornecedores, clientes, empregados, governo e a sociedade civil.

ludícibus, Martins e Gelbcke (2007) advertem que, para a informação contábil ser evidenciada de forma adequada, é necessário que atenda os atributos da confiabilidade, tempestividade, compreensibilidade e comparabilidade. No Quadro 3 são apresentadas as principais características qualitativas que as demonstrações devem apresentar para serem úteis aos usuários, conforme estabelece o CPC (2008).

\begin{tabular}{|c|c|}
\hline $\begin{array}{c}\text { Características } \\
\text { Qualitativas }\end{array}$ & Definição \\
\hline Compreensibilidade & $\begin{array}{l}\text { - A informação deve ser compreensível para ser útil; } \\
\text { - Presume-se que os usuários tenham um conhecimento razoável, } \\
\text { dos negócios, atividades econômicas e contabilidade e a disposição } \\
\text { de estudar as informações; } \\
\text { - As informações relevantes devem ser apresentadas apesar de sua } \\
\text { complexidade. }\end{array}$ \\
\hline Relevância & $\begin{array}{l}\text { - A informação relevante é aquela que influencia o usuário na } \\
\text { tomada de decisões; } \\
\text { - Deve ser considerada a materialidade da informação, ou seja, se a } \\
\text { sua omissão poderá gerar ou não uma distorção na decisão do } \\
\text { usuário. }\end{array}$ \\
\hline Confiabilidade & $\begin{array}{l}\text { - As demonstrações devem estar livres de erros ou vieses relevantes } \\
\text { e apresentar adequadamente aquilo que se propõe a apresentar; } \\
\text { - Deve representar adequadamente as transações e outros eventos } \\
\text { que ela diz apresentar. } \\
\text { - Deve dar ênfase à essência sobre a forma, à neutralidade, à } \\
\text { prudência e à integridade. }\end{array}$ \\
\hline Comparabilidade & $\begin{array}{l}\text { - Os usuários devem poder comparar as demonstrações contábeis de } \\
\text { uma entidade ao longo do tempo, a fim de identificar tendências na } \\
\text { sua posição patrimonial e financeira e no seu desempenho; } \\
\text { - Os usuários devem ser informados das práticas contábeis seguidas } \\
\text { na elaboração e suas alterações; }\end{array}$ \\
\hline
\end{tabular}

Quadro 3 - Características qualitativas das demonstrações contábeis

Fonte: elaboração própria com base no CPC (2008)

Para o CPC (2008), as demonstrações contábeis poderão ter a qualidade de suas informações comprometidas pela falta de equilíbrio entre as características qualitativas, pela ausência da tempestividade e falta de equilíbrio entre o custo e beneficio.

\section{PROCEDIMENTOS METODOLÓGICOS}

Esta pesquisa caracteriza-se como exploratória. Raupp e Beuren (2004, p. 80) destacam que "uma característica interessante da pesquisa exploratória consiste no 
aprofundamento de conceitos preliminares sobre determinada temática não contemplada de modo satisfatório anteriormente".

0 estudo exploratório foi realizado por meio de pesquisa documental. Em relação a esse procedimento, Raupp e Beuren (2004, p. 89) mencionam que "sua notabilidade é justificada no momento em que se podem organizar informações que se encontram dispersas, conferindo-lhe uma nova importância como fonte de consulta".

$\mathrm{Na}$ abordagem do problema, a pesquisa caracteriza-se como qualitativa. Richardson (1999, p. 80) afirma que "os estudos que empregam uma metodologia qualitativa podem descrever a complexidade de determinado problema, analisar a interação de certas variáveis, compreender e classificar processos dinâmicos vividos por grupos sociais".

A técnica de investigação utilizada consistiu da análise de conteúdo, definida por Bardin (1977, p. 42) como "um conjunto de técnicas de análise das comunicações, visando a obter, por procedimentos sistemáticos e objetivos de descrição do conteúdo das mensagens, indicadores quantitativos ou não, que permitam a inferência de conhecimentos relativos às condições de produção/recepção (variáveis inferidas) das mensagens".

A pesquisa foi realizada nas páginas eletrônicas dos quatro governos estaduais da região sudeste do Brasil. A seleção dessas entidades públicas estaduais decorre do fato de se presumir que existam níveis de evidenciação contábil e social diferenciados nesses quatro estados, seja por questões partidárias ou pelo porte, situação econômico-financeira do estado, características do estado e cultura organizacional,, apresentando-se desta forma com um custo político diferenciado das evidenciações.

Os dados para análise foram coletados nas páginas eletrônicas de cada entidade pública selecionada. Das informações disponibilizadas, foi avaliado inicialmente o nível de evidenciação compulsória estabelecida pela legislação, mais especificamente o que determinam a Lei $n^{\circ}$ 9.755/1998 e a Lei Complementar $n^{\circ} 101 / 2000$. Também foi avaliada a quantidade e qualidade da evidenciação contábil voluntária apresentada nas páginas eletrônicas destas entidades.

Para a análise dos níveis de divulgação contábil, utilizou-se a classificação de Hendriksen e Van Breda (1999) em mínima, justa e completa. Na análise das características qualitativas das evidenciações, foram utilizadas as definições do CPC (2008): compreensibilidade, relevância, confiabilidade e comparabilidade.

O estudo se limitou a identificar os níveis e qualidade das evidenciações contábeis, não se preocupando em identificar e comprovar os eventos que diferenciam os estados ou que limitam a apresentação das evidenciações. Outra limitação do estudo está na ausência de entrevistas com os gestores públicos desses estados, ou seja, a análise de conteúdo ficou restrita às páginas eletrônicas.

\section{ANÁLISE E INTERPRETAÇÃO DOS DADOS}

Nessa seção apresenta-se inicialmente a estrutura das páginas eletrônicas dos quatro governos estaduais pesquisados. Na seqüência são analisados os níveis e características qualitativas das evidenciações contábeis compulsórias e voluntárias publicadas. 


\subsection{ESTRUTURA DOS SÍTIOS DOS ESTADOS PESQUISADOS}

Inicialmente foram localizadas na rede mundial de computadores as páginas eletrônicas dos quatro governos estaduais selecionados: São Paulo (www.saopaulo.sp.gov.br), Rio de Janeiro (www.governo.rj.gov.br), Minas Gerais (www.mg.gov.br) e Espírito Santo (www.es.gov.br).

Na Figura 1 é apresentado um mapa sintético do conteúdo dos sítios pesquisados, permitindo a localização das informações sobre as contas públicas de cada Estado.
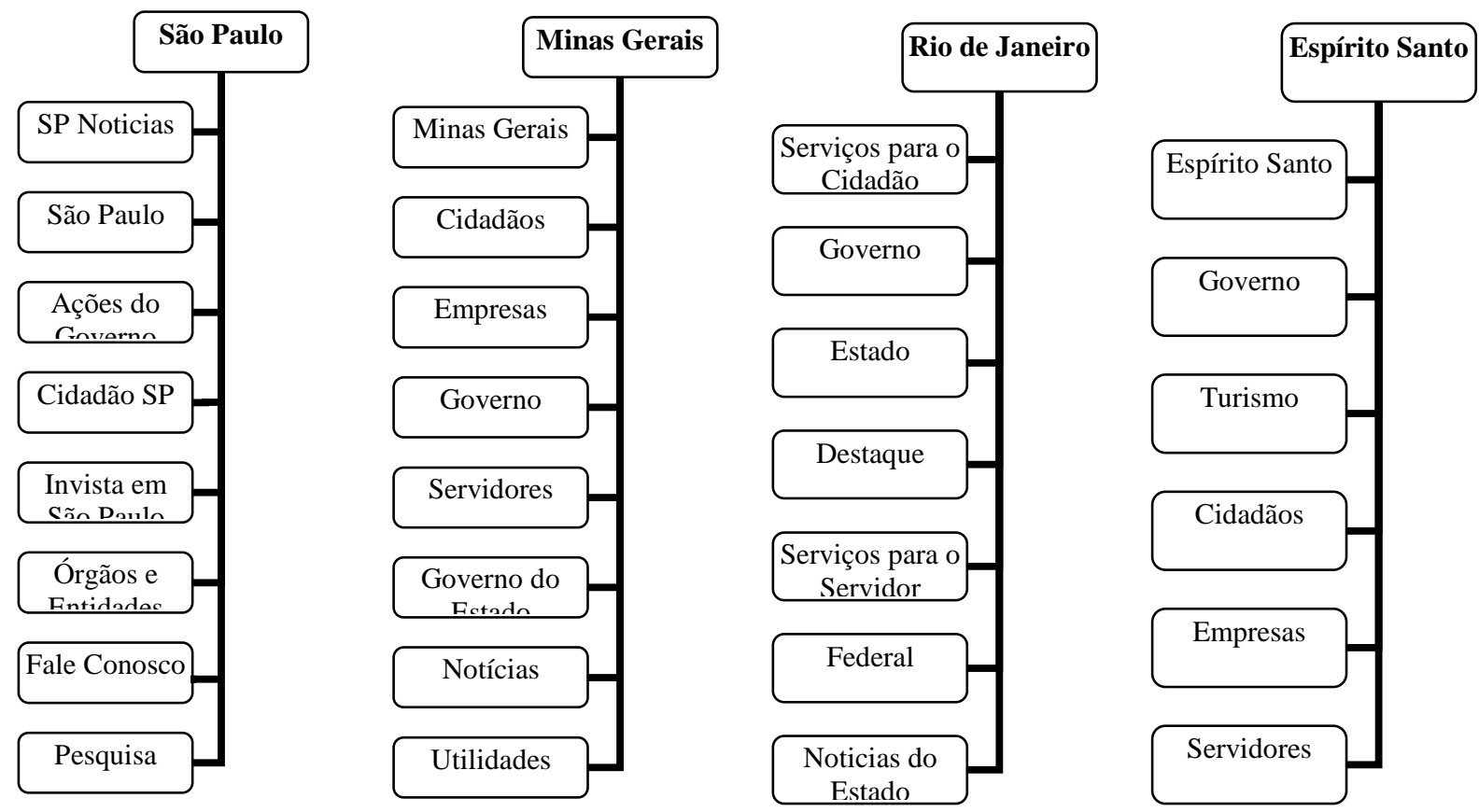

Figura 1 - Mapa sintético dos sítios analisados Fonte: elaboração própria.

Com base na estrutura apresentada na Figura 1, foi realizada a pesquisa nas páginas eletrônicas sobre as evidenciações compulsórias e voluntárias. Identificou-se que todos os Estados pesquisados possuem dentro da estrutura dos seus sítios algum link onde foram disponibilizadas as informações contábeis.

Constatou-se que todos publicam estas informações por meio das páginas das secretarias estaduais da fazenda. Estes acessos são possíveis por meio do link Governo para os governos dos Estados do Espírito Santo e Rio de Janeiro; link Governo do Estado na página eletrônica de Minas Gerais; link Órgãos e Entidades no governo do Estado de São Paulo.

Os governos dos Estados pesquisados disponibilizaram suas informações por meio dos seguintes links dentro das páginas das secretarias estaduais da fazenda: São Paulo em Prestando Contas, Minas Gerais em Contas Públicas, Rio de Janeiro em Transparência Fiscal e Espírito Santo em Contabilidade.

Nesta fase da análise destacou-se o governo do Estado de Minas Gerais, pela facilidade de localização das informações sobre as contas publicas. Apresenta um link de acesso na página principal do Governo do Estado indicando o acesso às informações. Para a localização das demonstrações dos demais Estados é necessária uma pesquisa por meio dos mapas de seus sítios. 


\subsection{EVIDENCIAÇÕES COMPULSÓRIAS}

$\mathrm{Na}$ segunda fase da pesquisa foram analisadas as evidenciações compulsórias de acordo com a disposição da Lei $n^{\circ}$ 9.755/1998 e da Instrução Normativa do Tribunal de Contas da União $n^{\circ} 28 / 1999$. Constatou-se que os quatro estados analisados possuem um cadastro na página eletrônica do Tribunal de Contas da União (http://www.contaspublicas.gov.br). No entanto, nenhum deles disponibilizou o link de acesso das contas públicas na página eletrônica deste órgão que permita o acesso às evidenciações contábeis compulsórias.

Por meio do acesso às informações disponíveis nas páginas eletrônicas realizou-se a análise das evidenciações compulsórias de acordo com a Lei $n^{\circ}$ 9.755/1998 e a Lei Complementar $n^{\circ}$ 101/2000 (Lei de Responsabilidade Fiscal - LRF) conforme demonstrado no Quadro 4.

\begin{tabular}{|c|c|c|c|c|}
\hline Evidenciações Compulsórias & SP & MG & RJ & $\mathbf{E S}$ \\
\hline a) Arrecadações (Lei no 9.755/1998) & Sim & Não & Sim & Sim \\
\hline $\begin{array}{l}\text { b) Relatório Resumido de Execução Orçamentária (Lei no 9.755/1998 e } \\
\text { LRF - LC n }{ }^{\circ} \text { 101/2000) }\end{array}$ & Sim & Sim & Sim & Sim \\
\hline c) Balanços (Lei no 9.755/1998) & Sim & Sim & Sim & $\operatorname{Sim}$ \\
\hline d) Contratos, aditivos e suas ratificações (Lei n ${ }^{\circ}$ 9.755/1998) & Não & Não & Não & Não \\
\hline e) Relações das compras (Lei nº 9.755/1998) & Não & Não & Não & Não \\
\hline f) Plano Plurianual (LRF - LC no 101/2000) & Sim & Sim & Sim & Sim \\
\hline g) Orçamento Anual (LRF - LC nº 101/2000 e Lei nº 9.755/1998) & Sim & Sim & Sim & Sim \\
\hline h) Lei de Diretrizes Anual (LRF - LC no 101/2000) & Sim & Sim & Sim & Sim \\
\hline i) Prestação de Contas e Parecer Prévio (LRF - LC no 101/2000) & Sim & Não & Não & Não \\
\hline j) Relatório de Gestão Fiscal (LRF - LC nº 101/2000) & Sim & Sim & Sim & Sim \\
\hline
\end{tabular}

Quadro 4 - Evidenciações contábeis compulsórias dos estados

Fonte: dados da pesquisa.

Constatou-se que nenhum dos estados analisados publicou integralmente o que dispõe a Lei $n^{\circ} 9.755 / 1998$, sendo que o Estado de São Paulo publica o maior volume de informações compulsórias de acordo com este dispositivo.

Verificou-se também que nenhum dos estados pesquisados publicou as informações sobre os contratos realizados pelos órgãos e a relação das compras efetuadas. A finalidade desses dois relatórios é o usuário poder efetivamente fiscalizar a aplicação dos recursos públicos, avaliando o volume de recursos gastos, a destinação dos materiais e serviços, o volume desembolsado em cada processo de compra, entre outros.

No que concerne às publicações compulsórias estabelecidas pela LRF, em seu art. 48, constatou-se que o governo do Estado de São Paulo publicou todos os relatórios exigidos pela LRF. Os demais Estados deixaram de apresentar as informações relativas à prestação de contas anuais e o parecer prévio do tribunal de contas do Estado.

O plano plurianual, orçamento anual e lei de diretrizes anual foram publicados por todos os estados nas páginas eletrônicas das secretarias de planejamento. Depreende-se dessa forma uma dispersão das informações compulsórias dentro das páginas eletrônicas dos estados.

A constatação de maior completude de publicação de informações disponibilizadas de acordo com o estabelecido pela LRF se justifica pela possibilidade de penalização do 
gestor, disposta na Lei $\mathrm{n}^{\circ}$ 10.028/2000, Lei de Crimes Fiscais, em seu art. 5, inc. I que estabelece:

Art. $5^{\circ}$. Constitui infração administrativa contra as leis de finanças públicas:

I - deixar de divulgar ou de enviar ao Poder Legislativo e ao Tribunal de Contas o relatório de gestão fiscal, nos prazos e condições estabelecidos em lei;

[...]

$\S 1^{\circ}$. A infração prevista neste artigo é punida com multa de trinta por cento dos vencimentos anuais do agente que the der causa, sendo o pagamento da multa de sua responsabilidade pessoal.

A falta de publicação por meio de mídia oficial do Estado das informações estabelecidas no Relatório de Gestão Fiscal (RGF) poderá refletir em penalização, exigindo do gestor maior atenção a este tipo de evidenciação compulsória.

\subsection{EVIDENCIAÇÕES VOLUNTÁRIAS}

A terceira fase da análise corresponde à identificação das evidenciações voluntárias apresentadas em cada um dos sítios, conforme demonstrado no Quadro 5. 


\begin{tabular}{|c|c|}
\hline Estados & Evidenciações \\
\hline São Paulo & $\begin{array}{l}\text { a) Despesas com cartões e adiantamentos; } \\
\text { b) Repasses a universidades; } \\
\text { c) Gráficos da evolução orçamentária e financeira; } \\
\text { d) Gráficos da evolução do resultado primário; } \\
\text { e) Gráficos da evolução dos gastos com pessoal; } \\
\text { f) Gráficos da evolução dos percentuais da dívida; } \\
\text { g) Gráficos da evolução dos gastos com saúde; } \\
\text { h) Gráficos da evolução dos gastos com educação } \\
\text { i) Gráficos da evolução dos investimentos; } \\
\text { j) Gráficos da evolução das receitas de competência estadual; } \\
\text { k) Gráficos da evolução dos gastos com despesas de custeio e investimentos; } \\
\text { l) Gráficos de evolução dos pagamentos de precatórios. }\end{array}$ \\
\hline Minas Gerais & $\begin{array}{l}\text { a) Calendário das publicações realizadas; } \\
\text { b) Gráficos da evolução orçamentária; } \\
\text { c) Gráficos da evolução do resultado primário; } \\
\text { d) Gráficos da evolução de arrecadação do ICMS (Impostos sobre a circulação de } \\
\text { mercadorias e serviços); } \\
\text { e) Gráficos da evolução dos investimentos; } \\
\text { f) Gráficos da evolução da receita corrente líquida; } \\
\text { g) Gráficos da evolução dos gastos com pessoal; } \\
\text { h) Gráficos da evolução dos gastos com saúde; } \\
\text { i) Gráficos da evolução dos gatos com educação. }\end{array}$ \\
\hline Rio de Janeiro & $\begin{array}{l}\text { a) Balancetes mensais; } \\
\text { b) Calendário das publicações realizadas; } \\
\text { c) Demonstração das receitas arrecadadas e despesas executadas do FECP (Fundo } \\
\text { Estadual de Controle da Pobreza); } \\
\text { d) Demonstração do resultado do fundo de previdência estadual; } \\
\text { e) Mapa demonstrativo das despesas pendentes de pagamento; } \\
\text { f) Boletim da transparência fiscal. } \\
\text { g) Gráficos da evolução das receitas; } \\
\text { h) Gráficos da evolução do resultado primário; } \\
\text { i) Gráficos da evolução dos gastos com pessoal; } \\
\text { j) Gráficos da evolução dos percentuais da dívida; } \\
\text { k) Gráficos da evolução dos gastos com saúde; } \\
\text { 1) Gráficos da evolução dos gastos com educação; } \\
\text { m) Gráficos da evolução dos valores totais enviados para os municípios; } \\
\text { n) Gráficos da evolução dos resultados do FUNDEB (Fundo Nacional de } \\
\text { Desenvolvimento da Educação Básica). }\end{array}$ \\
\hline Espírito Santo & a) Balancetes Mensais. \\
\hline
\end{tabular}

Quadro 5 - Evidenciações contábeis voluntárias dos estados

Fonte: dados da pesquisa.

No Quadro 5 evidencia-se uma grande variação em relação ao número de itens e forma de apresentação das informações entre os estados. O governo do Estado de São Paulo apresentou um conjunto mais significativo de evidenciações. Inclusive, foram evidenciadas as despesas com cartões e adiantamentos, que se referem tradicionalmente aos gastos de funcionários e gestores em viagens, estadias e alimentação. Destaca-se também o conjunto de gráficos de fácil entendimento por parte do cidadão, quanto ao comportamento dos gastos com pessoal, saúde, educação, investimentos, entre outros.

$\mathrm{Na}$ página eletrônica do governo do Estado de Minas Gerais foram identificadas somente informações de datas das publicações realizadas e alguns gráficos demonstrando as evoluções orçamentárias, investimentos, gastos com pessoal, saúde, educação, entre outros. O Estado do Rio de Janeiro publicou o maior conjunto de demonstrativos, dentre os 
quais se destacam os balancetes mensais, datas das publicações realizadas, demonstrações de fundos estaduais, mapa de despesas pendentes e um conjunto de gráficos. Destacou-se de forma menos interessante nesta análise o governo do Estado do Espírito Santo, que apresentou somente os balancetes mensais como evidenciações voluntárias.

De acordo com a Teoria da Legitimidade, estas entidades necessitam demonstrar constantemente à sociedade a sua importância e legitimar os seus atos, isto é, precisam evidenciar o cumprimento do contrato social existente entre o governo e a sociedade. Com custos políticos potencialmente elevados, os governos precisam estar atentos para não ter ameaçada a sua legitimidade. Ampliar evidenciações compulsórias e voluntárias pode contribuir no sentido de manter ou diminuir a possibilidade de perda da legitimidade.

\subsection{ANÁLISE DOS NÍVEIS E CARACTERÍSTICAS QUALITATIVAS DAS EVIDENCIAÇÕES}

Neste tópico foram analisados os níveis de evidenciação contábil apresentados pelos estados analisados e as características qualitativas das evidenciações contábeis.

\subsubsection{Níveis de evidenciação contábil compulsória e voluntária}

Para análise dos níveis de evidenciação contábil, buscaram-se as categorias preconizadas por Hendriksen e Van Breda (1999), conforme apresentado no Quadro 1, que classificam estes níveis em: divulgação adequada, justa e completa. Os parâmetros para o enquadramento dos níveis de evidenciação compulsória e voluntária nessas três categorias foram, respectivamente, os itens de evidenciação apontados nos Quadros 4 e 5 . Assim, no Quadro 6 apresentam-se os níveis de evidenciação compulsória e voluntária dos Estados analisados. 


\begin{tabular}{|c|c|c|c|c|c|c|c|c|c|}
\hline Estados & \multicolumn{3}{|c|}{ Adequada } & \multicolumn{3}{|c|}{ Justa } & \multicolumn{3}{|c|}{ Completa } \\
\hline SP & Satisfaz & $\begin{array}{c}\text { Satifaz } \\
\text { parcial } \\
\text { mente }\end{array}$ & $\begin{array}{c}\text { Não } \\
\text { satisfaz }\end{array}$ & Satisfaz & $\begin{array}{c}\text { Satifaz } \\
\text { parcial } \\
\text { mente }\end{array}$ & $\begin{array}{c}\text { Não } \\
\text { satisfaz }\end{array}$ & Satisfaz & $\begin{array}{c}\text { Satifaz } \\
\text { parcial } \\
\text { mente }\end{array}$ & $\begin{array}{l}\text { Não } \\
\text { satisfaz }\end{array}$ \\
\hline $\begin{array}{l}\text { Evidenciação } \\
\text { Compulsória }\end{array}$ & $\begin{array}{l}\mathrm{b}, \mathrm{c}, \mathrm{f}, \mathrm{g} \\
\mathrm{h}, \mathrm{i}, \mathrm{j}\end{array}$ & & $\mathrm{a}, \mathrm{d}, \mathrm{e}$ & $\begin{array}{l}\text { b,c,f,g } \\
\text {,h,i,j }\end{array}$ & $\mathrm{a}$ & $\mathrm{d}, \mathrm{e}$ & $\begin{array}{l}\text { b,c,f,g } \\
\text {,h,i,j }\end{array}$ & & $\mathrm{a}, \mathrm{d}, \mathrm{e}$ \\
\hline $\begin{array}{l}\text { Evidenciação } \\
\text { Voluntária }\end{array}$ & $\begin{array}{l}\text { a,b,c,d } \\
\mathrm{e}, \mathrm{f}, \mathrm{g}, \mathrm{h} \\
\mathrm{i}, \mathrm{j}, \mathrm{k}, \mathrm{l}\end{array}$ & & & $\begin{array}{l}\text { a,b, } \\
\mathrm{c}, \mathrm{de}, \mathrm{f}, \\
\mathrm{g}, \mathrm{h}, \mathrm{i}, \mathrm{j}, \\
\mathrm{k}, \mathrm{l}\end{array}$ & & & $\begin{array}{l}\mathrm{a}, \\
\mathrm{c}, \mathrm{d}, \mathrm{e}, \mathrm{f} \\
\mathrm{g}, \mathrm{h}, \mathrm{i}, \mathrm{j} \\
\mathrm{k}, \mathrm{l}\end{array}$ & $\mathrm{b}$ & \\
\hline \multicolumn{10}{|l|}{ MG } \\
\hline $\begin{array}{l}\text { Evidenciação } \\
\text { Compulsória }\end{array}$ & $\begin{array}{l}\mathrm{b}, \mathrm{c}, \mathrm{f}, \mathrm{g} \\
\mathrm{h}, \mathrm{j}\end{array}$ & & $\mathrm{a}, \mathrm{d}, \mathrm{e}, \mathrm{i}$ & $\begin{array}{l}\mathrm{b}, \mathrm{c}, \mathrm{f}, \mathrm{g} \\
\mathrm{h}, \mathrm{j}\end{array}$ & & $\mathrm{a}, \mathrm{d}, \mathrm{e}, \mathrm{i}$ & $\begin{array}{l}\mathrm{b}, \mathrm{c}, \mathrm{f}, \mathrm{g} \\
\mathrm{h}, \mathrm{j}\end{array}$ & & $\mathrm{a}, \mathrm{d}, \mathrm{e}, \mathrm{i}$ \\
\hline $\begin{array}{l}\text { Evidenciação } \\
\text { Voluntária }\end{array}$ & $\begin{array}{l}\text { a,b,c,d } \\
\text { e,f,g, } \\
h, i\end{array}$ & & & $\begin{array}{c}a, b, c, d \\
\text { e,f,g, } \\
\text { h,i }\end{array}$ & & & $\begin{array}{c}a, b, c, d \\
\text { e,f,g, } \\
\text { h,i }\end{array}$ & & \\
\hline \multicolumn{10}{|l|}{ RJ } \\
\hline $\begin{array}{l}\text { Evidenciação } \\
\text { Compulsória }\end{array}$ & $\begin{array}{l}\mathrm{b}, \mathrm{c}, \\
\mathrm{f}, \mathrm{g}, \mathrm{h}, \mathrm{j}\end{array}$ & & $\mathrm{a}, \mathrm{d}, \mathrm{e}, \mathrm{i}$ & $\begin{array}{l}\mathrm{b}, \\
\mathrm{f}, \mathrm{g}, \mathrm{h}, \mathrm{j}\end{array}$ & $\mathrm{a}, \mathrm{c}$ & $\mathrm{d}, \mathrm{e}, \mathrm{i}$ & $\begin{array}{l}\mathrm{b}, \mathrm{c}, \\
\mathrm{f}, \mathrm{g}, \mathrm{h}, \mathrm{j}\end{array}$ & & $\mathrm{a}, \mathrm{d}, \mathrm{e}, \mathrm{i}$ \\
\hline $\begin{array}{l}\text { Evidenciação } \\
\text { Voluntária }\end{array}$ & $\begin{array}{l}\mathrm{a}, \mathrm{b}, \mathrm{c}, \mathrm{d} \\
\mathrm{e}, \mathrm{f}, \mathrm{g}, \\
\mathrm{h}, \mathrm{i}, \mathrm{j}, \mathrm{k}, \\
\mathrm{l}, \mathrm{m}, \mathrm{n}\end{array}$ & & & $\begin{array}{l}\text { a,b,c,d } \\
\text {,e,f,g, } \\
\text { h,i,j,k, } \\
\text { l,m,n }\end{array}$ & & & & $\begin{array}{l}\mathrm{a}, \mathrm{b}, \mathrm{c}, \mathrm{d} \\
\mathrm{e}, \mathrm{f}, \mathrm{g}, \\
\mathrm{h}, \mathrm{i}, \mathrm{j}, \mathrm{k}, \\
\mathrm{l}, \mathrm{m}, \mathrm{n}\end{array}$ & \\
\hline \multicolumn{10}{|l|}{ ES } \\
\hline $\begin{array}{l}\text { Evidenciação } \\
\text { Compulsória }\end{array}$ & $\begin{array}{l}a, b, c, \\
f, g, h, j\end{array}$ & & $\mathrm{~d}, \mathrm{e}, \mathrm{i}$ & $\begin{array}{l}\text { a,b,c, } \\
\text { f,g,h,j }\end{array}$ & & $\mathrm{d}, \mathrm{e}, \mathrm{i}$ & $\begin{array}{l}\mathrm{b}, \mathrm{c}, \\
\mathrm{f}, \mathrm{g}, \mathrm{h}, \mathrm{j}\end{array}$ & $\mathrm{a}$ & $\mathrm{d}, \mathrm{e}, \mathrm{i}$ \\
\hline $\begin{array}{l}\text { Evidenciação } \\
\text { Voluntária }\end{array}$ & $\mathrm{a}$ & & & $\mathrm{a}$ & & & $\mathrm{a}$ & & \\
\hline
\end{tabular}

\section{Quadro 6 - Níveis de evidenciação da informação contábil dos estados}

Fonte: dados da pesquisa.

A divulgação adequada, aqui compreendida como aquela considerada a mínima necessária para que as informações possam ser compreendidas por parte de seus usuários, foi identificada em todos os estados, considerando-se a maioria das evidenciações compulsórias destacadas no Quadro 4. Merecem destaque os instrumentos de planejamento divididos em plano plurianual, orçamento anual, diretrizes orçamentárias. Dentre os relatórios que demonstram os resultados deste planejamento, ressaltam-se o Relatório Resumido de Execução Orçamentária (bimestral), o Relatório de Gestão Fiscal (quadrimestral) e o Balanço Anual. As evidenciações compulsórias não atendidas satisfatoriamente na maioria dos estados são: a) Arrecadações (Lei $n^{\circ}$ 9.755/1998); d) Contratos, aditivos e suas ratificações (Lei $\left.n^{\circ} 9.755 / 1998\right)$; e) Relações das compras (Lei $n^{\circ}$ 9.755/1998); e i) Prestação de Contas e Parecer Prévio (LRF - LC 101/2000).

A análise das evidenciações voluntárias foi considerada de nível adequado em três estados, pela facilidade no entendimento das informações apresentadas. Em um dos estados analisados foram publicados somente os balancetes mensais na categoria de evidenciações voluntárias, o que dificulta a análise da qualidade da gestão pública por parte dos usuários. 
Em se analisando o nível de evidenciação justa foi possível identificar dois extremos, sendo disponibilizadas todas as demonstrações a todos os usuários ao mesmo tempo. No entanto, a compreensibilidade destas informações fica prejudicada na maioria das evidenciações compulsórias, uma vez que são de difícil compreensão pelo usuário cidadão. As evidenciações voluntárias, por sua vez, podem ser compreendidas com maior facilidade por este usuário, merecendo destaque o conjunto de gráficos apresentados por todos os estados. Vale ressaltar que a ausência desse tipo de evidenciações por um dos estados limita a compreensibilidade por parte de seus usuários.

$\mathrm{Na}$ análise da estrutura das páginas eletrônicas quanto às informações completas ou relevantes das evidenciações apresentadas, constatou-se que o nível de divulgação é diferenciado entre os estados. Nas evidenciações compulsórias, o Estado de São Paulo apresentou um maior nível, no entanto em nenhum dos estados ela é completa. Da mesma forma as evidenciações voluntárias são limitadas. Destaca-se que na entidade pública a informação completa é constituída de um grande número de demonstrações sintéticas e analíticas. Constatou-se que em nenhum dos estados analisados foram localizadas demonstrações contábeis de caráter social (balanço social), análise de custos dos serviços públicos oferecidos (relatórios de custos), análise de balanços e relatórios analíticos dos gastos públicos.

\subsubsection{Características qualitativas das informações contábeis evidenciadas}

$\mathrm{Na}$ análise das características qualitativas que as informações contábeis devem apresentar para que sejam úteis aos usuários, foi observado o que estabelece o CPC (2008). Como parâmetros para a análise das características qualitativas das evidenciações, foram utilizadas as definições apresentadas no Quadro 3. No Quadro 7 são demonstrados os resultados das características qualitativas das demonstrações contábeis analisadas. 


\begin{tabular}{|c|c|c|c|c|c|c|c|c|c|c|c|c|}
\hline \multirow{2}{*}{$\frac{\text { Estados }}{\text { SP }}$} & \multicolumn{3}{|c|}{$\begin{array}{c}\text { Compreensibilid } \\
\text { ade }\end{array}$} & \multicolumn{3}{|c|}{ Relevância } & \multicolumn{3}{|c|}{ Confiabilidade } & \multicolumn{3}{|c|}{$\begin{array}{c}\text { Comparabilidad } \\
\text { e }\end{array}$} \\
\hline & Total & $\begin{array}{c}\text { Parci } \\
\text { al } \\
\end{array}$ & Nula & Total & $\begin{array}{c}\text { Parci } \\
\text { al } \\
\end{array}$ & Nula & Total & $\begin{array}{c}\text { Parci } \\
\text { al }\end{array}$ & Nula & Total & $\begin{array}{c}\text { Parci } \\
\text { al }\end{array}$ & Nula \\
\hline $\begin{array}{l}\text { Evidenciação } \\
\text { Compulsória }\end{array}$ & $\begin{array}{l}\mathrm{a}, \mathrm{b}, \\
\mathrm{c}, \mathrm{f}, \mathrm{g} \\
\mathrm{h}, \mathrm{i}, \mathrm{j}\end{array}$ & & $\mathrm{d}, \mathrm{e}$ & $\begin{array}{l}\mathrm{a}, \mathrm{b}, \\
\mathrm{c}, \mathrm{f}, \mathrm{g} \\
\mathrm{h}, \mathrm{i}, \mathrm{j}\end{array}$ & & $\mathrm{d}, \mathrm{e}$ & & $\begin{array}{l}\mathrm{a}, \mathrm{b}, \\
\mathrm{c}, \mathrm{f}, \mathrm{g} \\
\mathrm{h}, \mathrm{i}, \mathrm{j}\end{array}$ & & $\begin{array}{l}\mathrm{a}, \mathrm{b} \\
\mathrm{c}, \mathrm{f}, \mathrm{g} \\
\mathrm{h}, \mathrm{i}, \mathrm{j}\end{array}$ & & $\mathrm{d}, \mathrm{e}$ \\
\hline $\begin{array}{l}\text { Evidenciação } \\
\text { Voluntária }\end{array}$ & $\begin{array}{c}\mathrm{a}, \mathrm{b}, \\
\mathrm{c}, \mathrm{d}, \\
\mathrm{e}, \mathrm{f}, \mathrm{g} \\
\mathrm{h}, \mathrm{i}, \mathrm{j} \\
\mathrm{k}, \mathrm{l}\end{array}$ & & & $\begin{array}{l}\mathrm{a}, \mathrm{b}, \\
\mathrm{c}, \mathrm{d}, \\
\mathrm{e}, \mathrm{f}, \mathrm{g} \\
\mathrm{h}, \mathrm{i}, \mathrm{j} \\
\mathrm{k}, \mathrm{l}\end{array}$ & & & & $\begin{array}{l}\mathrm{a}, \mathrm{b}, \\
\mathrm{c}, \mathrm{d}, \\
\mathrm{e}, \mathrm{f}, \mathrm{g} \\
\mathrm{h}, \mathrm{i}, \mathrm{j} \\
\mathrm{k}, \mathrm{l}\end{array}$ & & $\begin{array}{l}\mathrm{c}, \mathrm{d}, \\
\mathrm{e}, \mathrm{f}, \mathrm{g} \\
\mathrm{h}, \mathrm{i}, \mathrm{j} \\
\mathrm{k}, \mathrm{l}\end{array}$ & $a, b$ & \\
\hline \multicolumn{13}{|l|}{$\mathrm{MG}$} \\
\hline $\begin{array}{l}\text { Evidenciação } \\
\text { Compulsória }\end{array}$ & $\begin{array}{l}\mathrm{b}, \mathrm{c}, \mathrm{f} \\
\mathrm{g}, \mathrm{h}, \\
\mathrm{j}\end{array}$ & & $\begin{array}{l}\mathrm{a}, \mathrm{d}, \\
\mathrm{e}, \mathrm{i}\end{array}$ & $\begin{array}{l}\mathrm{b}, \mathrm{c}, \mathrm{f} \\
\mathrm{g}, \mathrm{h}, \\
\mathrm{j}\end{array}$ & & $\begin{array}{l}\mathrm{a}, \mathrm{d}, \\
\mathrm{e}, \mathrm{i}\end{array}$ & & $\begin{array}{l}\mathrm{b}, \mathrm{c}, \mathrm{f} \\
\mathrm{g}, \mathrm{h}, \\
\mathrm{j}\end{array}$ & $\begin{array}{l}\mathrm{a}, \mathrm{d}, \\
\mathrm{e}, \mathrm{i}\end{array}$ & $\begin{array}{c}\mathrm{b}, \mathrm{c}, \mathrm{f} \\
\mathrm{g}, \mathrm{h}, \\
\mathrm{j}\end{array}$ & & $\begin{array}{l}\mathrm{a}, \mathrm{d}, \\
\mathrm{e}, \mathrm{i}\end{array}$ \\
\hline $\begin{array}{l}\text { Evidenciação } \\
\text { Voluntária }\end{array}$ & $\begin{array}{l}\mathrm{a}, \mathrm{b}, \\
\mathrm{c}, \mathrm{d}, \\
\mathrm{e}, \mathrm{f}, \mathrm{g} \\
\mathrm{h}, \mathrm{i}\end{array}$ & & & $\begin{array}{l}\mathrm{b}, \mathrm{c}, \\
\mathrm{d}, \mathrm{e}, \mathrm{f} \\
\mathrm{g}, \mathrm{h}, \\
\mathrm{i}\end{array}$ & & $\mathrm{a}$ & & $\begin{array}{l}\text { a,b, } \\
\mathrm{c}, \mathrm{d}, \\
\mathrm{e}, \mathrm{f}, \mathrm{g} \\
\mathrm{h}, \mathrm{i}\end{array}$ & & $\begin{array}{l}\mathrm{a}, \mathrm{b}, \\
\mathrm{c}, \mathrm{d}, \\
\mathrm{e}, \mathrm{f}, \mathrm{g} \\
\mathrm{h}, \mathrm{i}\end{array}$ & & \\
\hline \multicolumn{13}{|l|}{$\mathrm{RJ}$} \\
\hline $\begin{array}{l}\text { Evidenciação } \\
\text { Compulsória }\end{array}$ & $\begin{array}{l}a, b, \\
c, \\
f, g, h \\
, j\end{array}$ & & $\mathrm{~d}, \mathrm{e}, \mathrm{i}$ & $\begin{array}{l}\mathrm{a}, \mathrm{b}, \\
\mathrm{c}, \mathrm{f}, \mathrm{g} \\
\mathrm{h}, \mathrm{j}\end{array}$ & & $\mathrm{d}, \mathrm{e}, \mathrm{i}$ & & $\begin{array}{l}\mathrm{a}, \mathrm{b}, \\
\mathrm{c}, \mathrm{f}, \mathrm{g} \\
\mathrm{h}, \mathrm{j}\end{array}$ & $\mathrm{d}, \mathrm{e}, \mathrm{i}$ & $\begin{array}{l}\mathrm{a}, \mathrm{b}, \\
\mathrm{c}, \mathrm{g}, \\
\mathrm{h}, \mathrm{j}\end{array}$ & & $\mathrm{d}, \mathrm{e}, \mathrm{i}$ \\
\hline $\begin{array}{l}\text { Evidenciação } \\
\text { Voluntária }\end{array}$ & $\begin{array}{l}\mathrm{a}, \mathrm{b}, \\
\mathrm{c}, \mathrm{d}, \\
\mathrm{e}, \mathrm{f}, \mathrm{g} \\
\mathrm{h}, \mathrm{i}, \mathrm{j} \\
\mathrm{k}, \mathrm{l}, \\
\mathrm{m}, \mathrm{n}\end{array}$ & & & $\begin{array}{l}\mathrm{a}, \mathrm{c}, \\
\mathrm{d}, \mathrm{e}, \mathrm{f} \\
\mathrm{g}, \mathrm{h}, \\
\mathrm{i}, \mathrm{j}, \mathrm{k}, \\
\mathrm{l}, \mathrm{m}, \\
\mathrm{n}\end{array}$ & & $\mathrm{b}$ & & $\begin{array}{l}\mathrm{a}, \mathrm{b}, \\
\mathrm{c}, \mathrm{d}, \\
\mathrm{e}, \mathrm{f}, \mathrm{g} \\
\mathrm{h}, \mathrm{i}, \mathrm{j} \\
\mathrm{k}, \mathrm{l} \\
\mathrm{m}, \mathrm{n}\end{array}$ & & $\begin{array}{l}\mathrm{a}, \mathrm{b}, \\
\mathrm{c}, \mathrm{d}, \\
\mathrm{e}, \mathrm{f}, \mathrm{g} \\
\mathrm{h}, \mathrm{i}, \mathrm{j} \\
\mathrm{k}, \mathrm{l} \\
\mathrm{m} . \mathrm{n}\end{array}$ & & \\
\hline \multicolumn{13}{|l|}{$\mathrm{ES}$} \\
\hline $\begin{array}{l}\text { Evidenciação } \\
\text { Compulsória }\end{array}$ & $\begin{array}{l}a, b, \\
c, \\
f, g, h \\
, j\end{array}$ & & $\mathrm{~d}, \mathrm{e}, \mathrm{i}$ & $\begin{array}{l}a, b, \\
c, f, g \\
, h, j\end{array}$ & & $\mathrm{~d}, \mathrm{e}, \mathrm{i}$ & & $\begin{array}{l}\mathrm{a}, \mathrm{b}, \\
\mathrm{c}, \mathrm{f}, \mathrm{g} \\
\mathrm{h}, \mathrm{j}\end{array}$ & $\mathrm{d}, \mathrm{e}, \mathrm{i}$ & $\begin{array}{l}\mathrm{a}, \mathrm{b} \\
\mathrm{c}, \mathrm{f}, \mathrm{g} \\
\mathrm{h}, \mathrm{j}\end{array}$ & & $\mathrm{d}, \mathrm{e}, \mathrm{i}$ \\
\hline $\begin{array}{l}\text { Evidenciação } \\
\text { Voluntária }\end{array}$ & & $\mathrm{a}$ & & & $\mathrm{a}$ & & & A & & & & $\mathrm{a}$ \\
\hline
\end{tabular}

Quadro 7 - Características qualitativas das demonstrações contábeis dos estados Fonte: dados da pesquisa

Pela complexidade das evidenciações compulsórias, torna-se difícil a compreensibilidade das informações apresentadas por estes relatórios. Somente usuários com conhecimento contábil no setor público conseguem compreender estes relatórios. As evidenciações voluntárias são possíveis de serem compreendidas pela maioria dos usuários, uma vez que estes relatórios são simplificados, claros e objetivos, dentro daquilo que se propõem apresentar. 
As evidenciações compulsórias são relevantes na tomada de decisão principalmente para os órgãos de fiscalização, assim, as informações são relevantes para estes usuários. Para os demais usuários estes relatórios apresentam pouca influência em suas decisões, pois, a sua complexidade impede uma interpretação adequada e o seu nível de detalhamento é limitado. As evidenciações voluntárias são relevantes para os usuários em sua tomada de decisão. No entanto, a limitação dos níveis destes relatórios impede que o usuário tome a decisão adequada, ou seja, a relevância é compreendida como toda informação importante na tomada de decisão. Nenhum dos estados disponibilizou todas as informações relevantes a todos os usuários.

$\mathrm{Na}$ análise da confiabilidade das evidenciações compulsórias destaca-se a ausência dos pareceres dos tribunais de contas dos estados, dos órgãos de controle interno ou da auditoria interna e do julgamento das contas apresentado pelas assembléias legislativas. As evidenciações voluntárias da mesma forma, não apresentaram a comprovação do acompanhamento e análise dos órgãos de fiscalização, no entanto, demonstram uma preocupação maior com a essência do que a forma.

No que se refere à característica da comparabilidade, as evidenciações compulsórias apresentadas pelos estados permitem que o usuário analise a gestão comparando os valores orçados e realizados no exercício financeiro. A publicação simultânea das informações de dois ou mais exercícios subseqüentes não foi identificada em nenhum relatório analisado, impedindo, dessa forma, uma análise da evolução das arrecadações, gastos, resultados financeiros e econômicos de cada estado. As evidenciações voluntárias da maioria dos estados, permitem a comparação da evolução de alguns índices, sendo limitadas aos gráficos, impedindo uma análise vertical, horizontal ou outros indicadores financeiros e econômicos.

Embora o foco do Comitê de Pronunciamentos Contábeis (CPC) esteja voltado às entidades privadas, as características qualitativas estabelecidas apresentam conotação geral de qualidade das informações evidenciadas aos usuários da informação e, por isso, merecem também atenção nas entidades públicas. Como as informações compulsórias se revestem de formalismos que por vezes dificultam seu entendimento por pessoas menos versadas no assunto, é importante que as entidades públicas complementem as evidenciações com informações voluntárias.

\subsection{ANÁLISE DA LEGITIMIDADE E CUSTO POLÍTICO}

A redução do custo político e a conquista, manutenção ou recuperação da legitimidade na gestão pública implicam atenção também à evidenciação de informações contábeis. Como visto em Dantas, Zendersky e Niyama (2004), não basta divulgar, é preciso divulgar com qualidade, oportunidade e clareza, observando a tempestividade da informação, o seu detalhamento e a relevância necessários. Para isso é preciso que a entidade pública divulgue informações, tanto quantitativas como qualitativas, compulsórias e voluntárias, que possibilitem aos usuários ter uma compreensão precisa e completa das atividades desenvolvidas.

Nesse sentido é que se realizou nas páginas eletrônicas dos governos estaduais da região sudeste do Brasil análise das evidenciações compulsórias, conforme estabelecido pela Lei $n^{\circ}$ 9.755/1998 e Lei Complementar $n^{\circ}$ 101/2000, e voluntárias. Também foram analisadas as características qualitativas das informações contábeis definidas pelo Comitê de Pronunciamentos Contábeis (CPC) em seu Pronunciamento Conceitual Básico: compreensibilidade, relevância, confiabilidade e comparabilidade das demonstrações. Para determinar os níveis de evidenciação contábil, consideraram-se as categorias estabelecidas por Hendriksen e Van Breda (1999), que consistem de divulgação adequada, justa e completa. 
Os resultados da pesquisa denotam que a evidenciação de informações contábeis nas páginas eletrônicas não atende de forma completa as quatro características qualitativas (compreensibilidade, relevância, confiabilidade e comparabilidade) e os três níveis de evidenciação pesquisados (divulgação adequada, justa e completa) e nem mesmo todas as evidenciações compulsórias estabelecidas na Lei $n^{\circ} 9.755 / 1998$ e na Lei Complementar $n^{\circ}$ 101/2000 para as entidades públicas.

Conforme abordado na revisão de literatura, organizações com custos políticos potencialmente elevados, quando se sentem ameaçadas na sua legitimidade, necessitam ampliar as evidenciações compulsórias e voluntárias, recuperando ou diminuindo a possibilidade de perda da legitimidade. Considerando-se os níveis de evidenciação compulsória e voluntária apresentados pelos governos estaduais analisados e a qualidade da evidenciação das informações contábeis constada, depreende-se que:

a) os Estados analisados não se sentem ameaçados em sua legitimidade perante a sociedade;

b) os Estados analisados não consideram o aumento do nível e qualidade da evidenciação como elementos essenciais para a manutenção da legitimidade;

c) os Estados analisados consideram o custo político do aumento dos níveis e qualidade das evidenciações frente à perda da legitimidade.

É importante ressaltar que não se pode afirmar que o nível e a qualidade das informações contábeis evidenciadas estão diretamente relacionados à legitimidade e ao custo político, uma vez que não se investigou se os gestores públicos dos respectivos estados conhecem essas teorias. No entanto, de acordo com Silva e Sancovschi (2006), a teoria da legitimidade e a hipótese do custo político ajudam na explicação do aumento da evidenciação social, principalmente quando existe pressão pública. Desse modo, os gestores públicos ampliam as evidenciações de aspecto social, para ampliar a sua legitimidade e evitar a intervenção política em suas atividades.

Fazendo-se um comparativo dos achados da pesquisa, observa-se que o Estado de São Paulo é que mais evidencia e melhor atende aos quesitos da qualidade da informação considerados. Na seqüêencia vem o Estado de Minas Gerais e o Estado do Rio de Janeiro. Por último está o Estado do Espírito Santo. Coincidência ou não, o nível e a qualidade da informação contábil evidenciada está relacionada ao número de habitantes de cada estado. O Estado de São Paulo tem a maior população do país e na região sudeste do Brasil o Espírito Santo é o menor Estado.

Além do maior número de pessoas que devem cobrar mais transparência dos atos do governador em decorrência do contingente populacional, respectivamente nos estados de São Paulo, Rio de Janeiro, Minas Gerais e Espírito Santo, há maior representação econômica e política desses estados na ordem apresentada. Por conseguinte, de acordo com a teoria da legitimidade e da hipótese do custo político, a organização necessita demonstrar constantemente à sociedade a sua importância e legitimar os seus atos.

\section{CONCLUSÕES}

O estudo objetivou analisar a evidenciação de informações contábeis que os governos estaduais da região sudeste do Brasil disponibilizam em suas páginas eletrônicas. Para alcançar o objetivo foi realizada uma pesquisa exploratória, por meio de análise documental, considerando como documentos as evidenciações contábeis nas páginas eletrônicas dos quatro governos estaduais da região sudeste do Brasil. 
Inicialmente foi verificada a formação da estrutura das páginas eletrônicas dos estados analisados. Na análise das evidenciações compulsórias estabelecidas pela Lei Complementar $n^{\circ} 101 / 2000$ e da Lei $n^{\circ}$ 9.755/1998, constatou-se que nenhum dos estados pesquisados cumpre integralmente o que é determinado pela legislação. Destaca-se o Estado de São Paulo pelo maior número de informações disponibilizadas. Quanto às evidenciações voluntárias apresentadas, destaca-se o governo do Estado de São Paulo, que apresenta o maior volume de publicações. Outro fator observado foi o limitado número de evidenciações voluntárias apresentadas pelos quatro estados.

Foram avaliados os níveis de evidenciação adequada, justa e completa, conforme proposto por Hendriksen e Van Breda (1999) e analisada a qualidade das demonstrações de acordo com a definição do CPC (2008), como compreensíveis, relevantes, confiáveis $e$ comparáveis. A informação apresentada atende de modo geral o nível mínimo exigido. 0 nível justo foi identificado na maioria das evidenciações. Satisfazendo parcialmente o nível de evidenciação completa em todas as evidenciações voluntárias e compulsórias. A maioria das evidenciações é de difícil entendimento para o usuário principal (cidadão). Nenhuma página eletrônica apresenta o acompanhamento e o parecer de auditoria, do controle interno ou outros responsáveis que aumentam a sua confiabilidade. As evidenciações compulsórias são de difícil comparação entre os exercícios, diminuindo a sua importância como suporte na tomada de decisão para o usuário.

Considerando-se os quatro governos estaduais da região sudeste analisados, concluise que a evidenciação de informações contábeis nas páginas eletrônicas não atende de forma completa as quatro características qualitativas e nem mesmo os três níveis de evidenciação pesquisados. $\mathrm{Na}$ análise foi possível constatar que as evidenciações compulsórias e voluntárias publicadas em suas páginas eletrônicas são limitadas. Nenhum dos quatro estados pesquisados apresenta evidenciações de forma completa, que possam efetivamente atender totalmente as necessidades do seu principal usuário aqui identificado como o cidadão.

Diante das limitações do estudo, recomenda-se a realização de uma pesquisa envolvendo os 27 estados brasileiros para identificar os níveis e as características qualitativas das evidenciações contábeis apresentadas pelos governos estaduais. Recomenda-se também que seja utilizada como estratégia de pesquisa outra forma de coleta de dados, por exemplo entrevistas com os gestores públicos estaduais, para verificar se buscam de modo consciente ampliar ou recuperar a legitimidade de seus atos e minimizar o custo político por meio da evidenciação contábil. Dado a precariedade de estudos na área pública, sugere-se avaliar a própria teoria de legitimidade e hipóteses do custo político para empresas públicas.

\section{REFERÊNCIAS}

AQUINO, W. de; SANTANA, A. C. de. Evidenciação. Caderno de Estudos, FIPECAFI, n. 5, p. $1-40$, jun. $/ 1992$.

BARDIN, L. Análise de conteúdo. Tradução de Luís Antero Reto e Augusto Pinheiro. Lisboa: Edições 70, 1977.

BISPO, J. de S.; et al. A importância dos dados contábeis para a relação entre carga tributária, tamanho e setor econômico das empresas brasileiras. In: XIV CONGRESSO BRASILEIRO DE CUSTOS, João Pessoa, 2007. Anais do XIV Congresso Brasileiro de Custos. São Leopoldo: ABCustos, 2007. 
BRASIL. Constituição da República Federativa do Brasil: 1988. 23. ed. Brasília: Câmara dos Deputados, Coordenação de Publicações, 2004.

Lei $n^{\circ}$ 4.320/1964. Estatui Normas Gerais de Direito Financeiro para elaboração e contrôle dos orçamentos e balanços da União, dos Estados, dos Municípios e do Distrito Federal. Disponível em: <www.planalto.gov.br>. Acesso em 5 jul. 2008.

. Lei no 9.755/1998. Dispõe sobre a criação de "homepage" na "Internet", pelo Tribunal de Contas da União, para divulgação dos dados e informações que especifica, e dá outras providências. Disponível em: <www.planalto.gov.br>. Acesso em 5 jul. 2008.

. Lei Complementar $n^{\circ} 101 / 2000$. Estabelece normas de finanças públicas voltadas para a responsabilidade na gestão fiscal e dá outras providências. Disponível em: $<$ www.planalto.gov.br>. Acesso em 5 jul. 2008.

. Lei $n^{\circ}$ 10.028/2000. Altera o Decreto-Lei n. 2.848, de 7 de dezembro de 1940 Código Penal, a Lei n. 1.079, de 10 de abril de 1950, e o Decreto-Lei n. 201, de 27 de fevereiro de 1967. Disponível em: <http://www.planejamento.gov.br>. Acesso em 24 ago. 2008.

BOFF, M. L. Estratégias de legitimidade organizacional de Lindblom na evidenciação ambiental e social em relatórios da administração de empresas familiares. 2007. Dissertação (Mestrado em Ciências Contábeis) - Programa de Pós-Graduação em Ciências Contábeis da Universidade Regional de Blumenau, 2007.

COMITÊ DE PRONUNCIAMENTOS CONTÁBEIS. Pronunciamento Conceitual Básico: Estrutura conceitual para elaboração e apresentação das demonstrações contábeis. 2008.

DAFT, R. L. Teoria e projeto das organizações. 6. ed. Rio de Janeiro: LTC, 1999.

DALMÁCIO, F. Z.; PAULO, F. F. M. de. A Evidenciação Contábil: Publicação de aspectos sócio-ambientais e econômico-financeiros nas demonstrações contábeis. Brazilian Business Review, v.1, n. 2, p. 74-90, 2004.

DANTAS, J. A.; ZENDERSKY, H. C.; NIYAMA, J. K. A dualidade entre os benefícios do disclosure e a relutância das organizações em aumentar o grau de evidenciação. In: XXVIII EnANPAD, 2004, Curitiba-PR. Anais do XXVIII EnANPAD. Rio de Janeiro: ANPAD, 2004. CDROM.

DIAS FILHO, J. M.; Políticas de evidenciação contábil: Um estudo do poder preditivo e explicativo da teoria da legitimidade. In: XXXI EnANPAD, 2007, Rio de Janeiro-RJ. Anais do XXXI EnANPAD. Rio de Janeiro: EnANPAD, 2007. CD-ROM.

FREY, M. R.; FREY, I. A. Evidenciação social corporativa: estudo de caso longitudinal da empresa Souza Cruz S.A. In: 17 Congresso Brasileiro de Contabilidade, Santos/SP, 2004. Anais do $17^{\circ}$ Congresso Brasileiro de Contabilidade. Brasília/DF, CFC, 2004.

HENDRIKSEN, E. S.; VAN BREDA, M. F. Teoria da Contabilidade. Tradução da americana por Antonio Zoratto Sanvicente. São Paulo: Atlas, 1999.

IUDíCIBUS , S. de. Teoria da contabilidade. 7. ed. São Paulo: Atlas, 2004.

; LOPES, A. B. Teoria avançada da contabilidade. São Paulo: Atlas, 2004.

; MARTINS, E.; GELBCKE, E. R. Manual de contabilidade das sociedades por ações: aplicável às demais sociedades. 7. ed. São Paulo: Atlas, 2007.

KEY, K. G. Political cost incentives for earnings management in the cable television industry. Journal o Accounting and Economics, n. 23, p. 309-337, 1997. 
PLATT NETO, O. A.; CRUZ, F. da; VIEIRA, A. L. Transparência das contas públicas: um enfoque no uso da internet como instrumento de publicidade na UFSC. Revista Contemporânea de Contabilidade, v. 1, n ${ }^{\circ}$ 5, pp. 135-146, jan./jun. 2007.

RAUPP, F. M. BEUREN, I. M. Caracterização da pesquisa em Contabilidade. In. BEUREN, Ilse Maria (Org). Como elaborar trabalhos monográficos em contabilidade: teoria e prática. 2. ed. São Paulo: Atlas, 2004.

RICHARDSON, R. J. Pesquisa social: métodos e técnicas. 3. ed. São Paulo: Atlas, 1999.

SILVA, A. H. C.; SANCOVSCHI, M. Evidenciação social corporativa: estudo de caso da Empresa Petróleo Brasileiro S.A. In: XXX EnANPAD, 2006, Salvador/BA. Anais do XXX EnANPAD. Rio de Janeiro: ANPAD, 2006. CD-ROM.

TOLEDO JR., F. C. de. Lei de Responsabilidade Fiscal: comentada artigo por artigo. 3. ed. São Paulo: NJD, 2005.

TCU - Tribunal de Contas da União. Instrução Normativa $n^{\circ}$ 28/1999. Estabelece regras para a implementação da homepage Contas Públicas, de que trata a Lei $n^{\circ}$ 9.755/98. Disponível em: <www.tcu.gov.br>. Acesso em 5 jul. 2008.

\section{ENDEREÇO DOS AUTORES}

Universidade Regional de Blumenau

Centro de Ciências Sociais e Aplicadas

R. Antonio da Veiga, 140, sala D 202 - Victor Konder

Caixa-Postal: 1507

Blumenau, SC - Brasil

89012-900 